\title{
Oral Contraceptives and Breast Cancer Risk: A Study among the Bengalee Females of West Bengal, India
}

\author{
Abhishikta Ghosh Roy ${ }^{1,2 *}$, BN Sarkar ${ }^{1}$ and Arup Ratan Bandyopadhyay ${ }^{2}$ \\ ${ }^{1}$ DNA Laboratory, Anthropological Survey of India, Kolkata \\ ${ }^{2}$ Department of Anthropology, University of Calcutta, Kolkata \\ *Corresponding author: Abhishikta Ghosh Roy, DNA Laboratory, Anthropological Survey of India, Kolkata
}

Submission: March 28, 2018; Published: May 04, 2018

\begin{abstract}
Breast Cancer is the one of the diseases affecting the world wide women population. In Indian perspective, breast cancer is one of the leading cancers, being the most common carcinoma among the females in West Bengal. The present study attempts to understand the association of oral contraceptives use and breast cancer in Bengalee Hindu Caste Females of West Bengal. To best of the knowledge oral contraceptive use and breast cancer risk among the females is yet to be taken in consideration in Bengalee Hindu caste females. To achieve the purpose 108 diagnosed breast cancer patients were considered along with 120 age matched controls without the history of breast cancer in the family. Result indicated use of oral contraceptives have significant $(\mathrm{p}<0.001)$ association with breast cancer. Therefore, the present study vindicated other than genetic predisposition modification of reproductive and lifestyle factors might be taken into consideration in early prognosis of breast cancer among the studied population.
\end{abstract}

Keywords: Oral contraceptives; Breast cancer; Bengalee hindu females; West Bengal; India

\section{Introduction}

Cancer is the leading cause of death worldwide including India and second leading cause of death in developing countries [1]. According to Siddhartha Mukherjee, Cancer is the "emperor of all Maladies" [2]. Cancer can be reduced and controlled by implementing evidence based strategies for cancer prevention, early detection and management. One third of cancers could be cured if detected early and treated adequately, based on the observation that treatment is more effective at early stages. In addition, more than $30 \%$ of cancers could be prevented simply by behavioral changes that include abstinence from using tobacco, use of healthy diet, maintaining a healthy weight, being physically active and preventing infections that may cause cancer death [3].

According to the epidemiological studies, 80 to $90 \%$ of all cancers are due to environmental factors of which, lifestyle related factors are the most important and preventable. The major risk factors for cancer are tobacco, alcohol consumption, infections, dietary habits and behavioral factors. Dietary practices, reproductive and sexual practices account for 20 to $30 \%$ of cancers. Studies have shown that appropriate changes in lifestyle will reduce the mortality and morbidity caused due to cancer. This offers the prospect for initiating primary and secondary prevention measures for control and prevention [4]. Thus, nowadays it is believed that breast cancer is a complex multi-factorial, polygenic and multi-step process $[5,6]$.

Some studies have reported an increased risk of breast cancer among women who have had induced abortions $[7,8]$. In incomplete pregnancy, the breast is exposed only to the high estrogen levels of early pregnancy and thus may be responsible for the increased risk seen in these women. However, some other studies have found no association between abortions and increased risk of breast cancer [9].

To best of the knowledge oral contraceptive use and breast cancer risk among the females is yet to be taken in consideration in Bengalee Hindu caste females. The present study attempts to understand the association of oral contraceptives use and breast cancer in Bengalee Hindu Caste Females of West Bengal.

\section{Methodology}

Study participants included cases and controls ranging in age from 30-72 years. The cases included subjects visiting the main cancer referral centers of West Bengal; Cancer Center Welfare Home and Research Institute, Kolkata, National Medical College and Hospital, Kolkata. The controls were such selected that none of them had any personal or family history of breast cancer.

Data on reproductive performances included parity, age at first child, menarche, menopause, duration of breast feeding, physical activity and diet with detailed information regarding OCP use and abortion incidents. History of breast cancer and oncologic data was retrieved from the medical records after consent from the patients. Demographic data were also collected for all participants. 
Data collected were analyzed using SPSS 20.0. Binary logistic regression was used to assess the correlation of any other possible risk factors and the degree of their contribution to breast cancer. Oral contraceptive use has been defined as use of Oral Contraceptive pills for a total or more than 6 months. Women who never used oral contraceptives or who never used them for less than 6 months were classified as non-users.

\section{Results}

The use of oral contraceptives slightly increases the risk of breast cancer in current and recent users, cancers diagnosed in women who have used $\mathrm{OC}$ tend to be less clinically advanced than those detected in never users. OC users are generally younger women whose breast cancer risk is comparatively low. The risk seems to go back to normal over time since the pills are stopped. Women who stopped using oral contraceptives more than 10 years ago do not appear to have any increased breast cancer risk. Over the past 30 years, the levels of the female hormone estrogen in the combined pill have decreased. It is not yet clear whether the modern, low doses in the combined pill are associated with the same breast cancer risk as the older, higher dose pills. While the combined pill is the most commonly used contraceptive pill, some women use the progesterone only pill (or "mini pill"). There is currently not enough evidence to determine whether or not there is a link between other forms of hormone-based contraception and breast cancer.

There is a marked difference in users and non-users of oral contraceptives among the patients and controls. $65.7 \%$ of the patients and $40.6 \%$ of the controls are users of the oral contraceptives, whereas $34.3 \%$ of the patients and $58.6 \%$ of the controls are non-users of the same. Ever use of oral contraceptives increases the risk of having breast cancer by 2.77 times than nonusers (OR-2.77; 95\% $\mathrm{CI}=1.63$ to $4.71, \mathrm{p}<0.0001^{* * *}$ ).

\section{Discussion}

Age and family history are commonly considered to have effect on prognosis and survival of breast cancer. The present study revealed substantial variation in breast cancer risk among the mutation carriers, particularly in terms of age variation and cancer type which basically envisaged that the concomitant effect of genetic variability and environmental factors which eventually modify the expression of the status.

The implication of natural hormones specially the sex hormones on developing cancers such as endometrial cancer [9], breast and prostate cancer [10] (among sex organ related neoplasm) or colon cancer [11], gall bladder cancer [12], kidney cancer [13] etc. (non sex organ related neoplasm) have been reported globally. Furthermore, breast cancer risk is enhanced by increasing the duration of exposure to endogeneous hormones (Endogenous Hormones and Breast Cancer Collaborative Group, 2011). It has also been reported that age at menarche, parity and age at first full-term pregnancy are risk factors for breast cancer $[14,15]$. In addition to that breast cancer risk is associated with several reproductive factors. It is well established that breast cancer risk increases with early age at menarche [16].

Table 1: Distribution of oral contraceptives use among the cases and controls.

\begin{tabular}{|c|c|c|c|c|c|}
\hline & \multicolumn{2}{|c|}{ Patients } & \multicolumn{2}{|c|}{ Controls } & \multirow{2}{*}{ ODDS Ratio } \\
\hline & No. & $\%$ & No. & $\%$ & \\
\hline No & 37 & 34.3 & 75 & 58.6 & \multirow{3}{*}{$\begin{array}{c}2.7677^{* * *} \\
95 \% \mathrm{CI}=1.63-4.71\end{array}$} \\
\hline Yes & 71 & 65.9 & 52 & 40.6 & \\
\hline Total & 108 & 100 & 128 & 100 & \\
\hline
\end{tabular}

Furthermore, long-term users of Oral Contraceptives (OCs) were at a higher risk of breast cancer than never users. Association studies regarding current/recent use of OCs with breast cancer risk demonstrated heterogeneous results to the extent of increased risk [17] to no or weak association of OCs use among BRCA1 mutation carrier in Breast Cancer. In this context, the present study revealed significant association $(\mathrm{p}<0.0019)$ of prolong use (more than six months) of OCs and breast cancer in comparison (Table 1) to the controls and the use of OCs increased the risk of breast cancer by 2.77 times than those of non-users (OR-2.77; 95\% CI=1.63$4.71 ; \mathrm{p}<0.0001)$. The controversial effects of OCs on breast cancer have been studied extensively. But currently there is conflicting epidemiological evidence regarding the role of oral pills in causation of breast cancer, so it is difficult to make a blanket statement [18]. For instance, several studies have found no significant association between history of oral contraceptive uses and breast cancer but other studies have shown diametrically opposite results [19-21]. The present study also could not measure the relationship of breast cancer with duration, type, dosage, and pattern of OCs usage because most of the subjects were not able to recall the details. For the females those have mutated tumor suppressor genes like BRCA1, the gene already fails to perform its tumor suppressing activity; elevated estrogen and progesterone stimulate breast cell proliferation, finally uncontrolled growth leads to carcinoma. Studies have found association between the OCs usage and BRCA1 mutation carriers (American Cancer Society Report, 2010). However, paucity of literature has been found from Indian context [22]. The present study reports significant association $(\mathrm{p}<0.0019)$ between OCs and breast cancer from eastern India for the first time. Since, hormones are considered to play a role in the etiology of breast cancer therefore, it is likely that BRCA1 might have important regulation of growth and differentiation in hormonally responsive epithelial cells. In addition to that, breast and ovary being the main estrogen receptor sites, the increased levels of the estrogen due to prolonged consumption of oral contraceptives gets accumulated in these sites [23]. Such finding is similar to the present study mentioned earlier, which has significant association with use of OCs and increased breast cancer risk, while many studies have represented that exogenous hormonal factors such as estrogen replacement therapy and combined oral contraceptive use might cause to some extent increase in the risk for breast cancer [9]. 


\section{References}

1. Jemal A, Siegel R, Ward E, Xu J (2010) Cancer Statistics, 2010. CA Caner J Clin 60(5): 277-300.

2. Mukherjee, Siddhartha (2010) The Emperor of All Maladies: A Biography of Cancer. Scribner, New York, USA.

3. Danaei G, Vander HS, Lopez AD, Murray CJ, Ezzati M (2005) Causes of cancer in the world: comparative risk assessment of nine behavioral and environmental risk factors. Lancet 366(9499): 1784-1793.

4. Murthy NS, Mathew A (2004) Cancer epidemiology, prevention and control. Current Science 86(4): 518-527.

5. Beckmann MW, Niederacher D, Schnurch HG, Gusterson BA, Bender HG (1997) Multistep carcinogenesis of breast cancer and tumor heterogeneity. J Mol Med 75(6): 429-439.

6. Antoniou A, Pharoah PD, Narod S (2003) Average risks of breast and ovarian cancer associated with BRCA1 or BRCA2 mutations detected in case Series unselected for family history: a combined analysis of 22 studies. Am J Hum Genet 72(5): 1117-1130.

7. Newcomb PA, Storer BE, Longnecker MP, Mittendorf R, Greenberg ER, et al. (1996) Pregnancy termination in relation to risk of breast cancer. JAMA 275 (4): 283-287.

8. Zeng Y, Xu MS, Tan SQ, Yin L (2010) Analysis of the risk factors of breast cancer. 3: 622-623.

9. Key TJA, Beral V (1992) Sex hormones and cancer. In: Vainio H, Magee PN, McGregor DB, McMichael AJ (Eds.), Mechanisms of Carcinogenesis in Risk Identification. IARC Scientific Publications, Lyon, France, pp. 116 255.

10. Sharma BK, Ray A (2000) Breast and prostate cancer. Indian Journal of Clinical Biochemistry 15: 110.

11. English MA, Stewart PM, Hewison M (2001) Estrogen metabolism and malignancy: analysis of the expression and function of 17 betahydroxysteroid dehydrogenases in colonic cancer. Mol Cell Endocrinol 171(1-2): 53-60

12. Ray A, Gupta S (2001) Some facts about gall-bladder cancer. ICPO Newsletter 3: 6 .
13. Li SA, Klicka JK, Li JJ (1985) Estrogen 2- and 4-hydroxylase activity, catechol estrogen formation, and implications for estrogen carcinogenesis in the hamster kidney. Cancer Res 45(1): 181-185.

14. Kelsey J, Gammon MD, John EM (1993) Reproductive factors and breast cancer. Epidemiologic Reviews 15: 36-47.

15. Russo J, Russo IH (1997) Role of differentiation in the pathogenesis and prevention of breast cancer. Endocrine Related Cancer 4: 7-21.

16. Dumitrescu RG, Cotarla I (2005) Understanding breast cancer risk-where do we stand in 2005? J Cell Mol Med 9(1): 208-221.

17. Merethe K, Elisabete W, Tonje B, Ingemar P, Hans-Olov A, Eiliv Lund (2002) Use of oral contraceptives and breast cancer risk. the norwegianswedish women's lifestyle and health cohort study1. Cancer Epidemiol Biomarkers Prev 11(11): 1375-1381.

18. Collaborative Group on Hormonal Factors in Breast Cancer (2002) Breast cancer and Breastfeeding: collaborative reanalysis of individual data from 47 epidemiological studies in 30 countries, including 50302 women with breast cancer and 96973 women without the disease. Lancet 360(9328): 187-195.

19. Ahmad M (2003) Risk factors for breast cancer among women attending breast clinic in University Malaya Medical Centre Kuala Lumpur. NCD Malaysia 2: 23-31.

20. Jick H, Walker AM, Watkins RN (1980) Oral contraceptive and breast cancer. American Journal of Epidemiology 112: 577-585.

21. Yavari P, Mousavizadeh M, Sadrol-Hefazi B (2005) Reproductive characteristics and the risk of breast cancer: A case-control study in Iran. Asian Pac J Cancer Prev 6(3): 370-375.

22. Narod SA (2011) Screening of women at high risk for breast cancer Preventive Medicine 52: 127-30.

23. Helewa M, Winnipeg MB, Helmrich SP, Shapiro S, Rosenberg L, Kaufman DW, Slone D, Bain C, Miettinen OS, Stolley PD, Rosenshein NB, Knapp RC Leavitt T, Schottenfeld D, Engle RL , Levy M (1983) Risk factors for breast cancer. Am J Epidemiol 117(1): 35-45.
Creative Commons Attribution 4.0

International License

For possible submissions Click Here
Submit Article

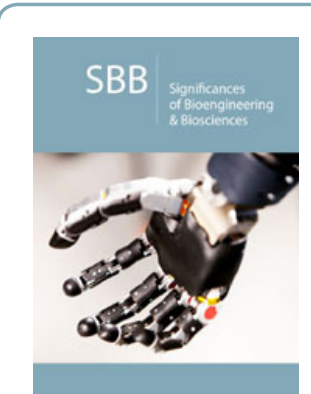

Significances of Bioengineering \& Biosciences

\section{Benefits of Publishing with us}

- High-level peer review and editorial services

- Freely accessible online immediately upon publication

- Authors retain the copyright to their work

- Licensing it under a Creative Commons license

- Visibility through different online platforms 